\title{
Prevenção da violência doméstica na perspectiva dos profissionais de saúde da família
}

\author{
Prevention of domestic violence in the perspective \\ of family health professionals
}

Maria de Lourdes Tavares Cavalcanti 1

\footnotetext{
1 Departamento de Medicina Preventiva da Faculdade de Medicina do Núcleo de Estudos de Saúde Coletiva, Universidade Federal do Rio de Janeiro. Av. Brigadeiro Trompowsky, s/no. Edifício do Hospital Universitário, 5o andar, Ala Sul, Ilha do Fundão, Rio de Janeiro, Brasil. lourdes@acd.ufrj.br
}

\begin{abstract}
This article presents observations and data concerning an exploratory study about professional perceptions and experiences in situations of domestic violence against children and adolescents in the Family Medical Program in Niterói/Rio de Janeiro. The opinion here expressed is that the insertion of a professional in the community in which he works, giving medical care to his patients in their homes, favours the identification and subsequent intervention in situations of domestic violence.
\end{abstract}

Key words Domestic Violence; Family Doctor; Violence Prevention
Resumo Este artigo apresenta as observações e dados de um estudo exploratório sobre as percepções e vivências de profissionais do Programa Médico de Família de Niterói em situações de violência doméstica contra crianças e adolescentes. A opinião expressa é de que a inserção do profissional na comunidade em que trabalha, facilitando o contato com os pacientes no local de moradia, favorece a identificação e subseqüente intervenção em situações de violência doméstica.

Palavras-chave Violência Doméstica; Médico de Família; Prevenção da Violência 


\section{Introdução}

A opinião manifestada neste artigo refere-se às possibilidades de prevenção da violência doméstica. É o relato de um estudo exploratório a respeito da violência doméstica contra crianças e adolescentes, na visão de profissionais dos módulos de médico de família na Cidade de Niterói, Estado do Rio de Janeiro. Constatou-se que no modelo assistencial de médico de família o profissional dificilmente deixa de identificar as situações de abuso familiar, sendo levado a abandonar a posição de distanciamento e tentar interferir nos processos de maus-tratos com os quais se depara (COOBS/FMS-Niterói, 1997).

\section{Pesquisando a violência doméstica em Niterói}

Como médica sanitarista da Fundação Municipal de Saúde (FMS) de Niterói e pesquisadora do Núcleo de Estudos de Saúde Coletiva (NESC) da Universidade Federal do Rio de Janeiro (UFRJ), tive a oportunidade, juntamente com residentes de saúde coletiva do NESC/ UFRJ, de desenvolver, em 1996 e 1997, uma investigação acerca da violência doméstica contra crianças e adolescentes em Niterói, visando à elaboração de uma proposta de intervenção voltada para os profissionais de saúde.

Preliminarmente foi realizado um estudo descritivo dos relatos de maus-tratos domésticos contra crianças e adolescentes ocorridos no Município, levando-se em consideração as informações registradas no Conselho Tutelar de Niterói com a finalidade de identificar as características gerais das situações de abuso familiar, obtendo um quadro dos casos oficialmente conhecidos. Foram identificados 128 registros de maus-tratos domésticos, nos quais os profissionais de saúde apareceram como agentes da denúncia em apenas $4(3,1 \%)$, sendo três desses registros referentes a casos de desnutrição grave, tendo ocorrido a denúncia por iniciativa da assistente social do posto de saúde. A informação relativa a cuidados prestados nos serviços de saúde, às vítimas de abuso doméstico, mostrou-se bastante falha nos prontuários investigados. Em 54 casos não constava esta informação no prontuário, resultando na elevada proporção de ignorados $(42,2 \%)$. Dos 74 casos em que se obteve o dado, $53(71,6 \%)$ não receberam nenhum tipo de assistência, e apenas 21 adolescentes e crianças maltratadas $(28,4 \%)$ foram levados a serviços de saúde para receber atendimento em função do dano causado pelo abuso (SUAPS/ FMS-Niterói, 1996).

A necessidade de conhecer o grau de envolvimento e atuação dos profissionais de saúde perante situações de violência familiar, e a limitação das informações encontradas no Conselho Tutelar induziram à decisão de se realizar um estudo qualitativo, junto a profissionais da rede municipal de saúde, com o propósito de conhecer as percepções, vivências e dificuldades profissionais perante situações de violência familiar. Foi definido que esta fase da pesquisa teria início pela investigação junto aos profissionais do Programa Médico de Família de Niterói. Esta escolha ocorreu em função da proposta assistencial do médico de família, em que as equipes trabalham inseridas nas comunidades, estabelecendo um vínculo com a população, o que foi considerado um facilitador para a identificação e intervenção em situações de violência familiar.

\section{O programa médico de família de Niterói}

O Programa Médico de Família (PMF) de Niterói originou-se a partir de um acordo de cooperação técnica firmado entre Brasil e $\mathrm{Cu}$ ba, em 1991. Teve início em 1992, e tem como inspiração o modelo cubano de medicina familiar, tendo sido adaptado às peculiaridades do sistema de saúde local. É implementado pela Fundação Municipal de Saúde de Niterói juntamente com associações de moradores do município. Estabelece a vinculação entre a população de determinada localidade e a equipe básica dos módulos de médicos de família, formada por um médico generalista e uma auxiliar de enfermagem, que geralmente mora na própria comunidade. Todos os profissionais são contratados por 40 horas semanais, com salários superiores aos pagos pela Fundação Municipal de Saúde aos funcionários.

Entre os objetivos do programa encontrase o de enfatizar a atenção primária, com base no desenvolvimento de ações preventivas que busquem minimizar o quadro de morbimortalidade do município. Aliam-se a estas ações as atividades de natureza curativa e a promoção de assistência social. A proposta é que o programa médico de família funcione como a porta de entrada no sistema de saúde, 
em um modelo assistencial que tem como base os princípios de hierarquização, integralidade e adscrição de clientela (Tuesta, 1997).

\section{Pesquisando a violência doméstica numa comunidade assistida por médicos de família}

A análise dos casos de maus-tratos domésticos atendidos no Conselho Tutelar foi apresentada e debatida com os coordenadores e supervisores do Programa Médico de Família, propondo-se a realização de um estudo sobre a questão junto às equipes do programa. Posteriormente foi realizado um encontro de sensibilização com estas equipes, expondo-se a proposta de investigação e convidando os interessados a participar. Nesse encontro, praticamente todos os presentes (médicos e auxiliares de enfermagem) demonstraram grande interesse na proposta da pesquisa, relatando situações vivenciadas no trabalho, e demonstrando necessidade premente de discutir a atuação do profissional perante situações de maus-tratos. Quase todas as equipes se dispuseram a ser entrevistadas.

A narrativa a seguir provém das observações e dos dados de entrevistas realizadas com as equipes do módulo de médico de família localizado no morro da Ilha da Conceição. Foram entrevistadas duas médicas e as três auxiliares de enfermagem. No período em que foram realizadas as entrevistas, uma das médicas estava de licença-maternidade sendo substituída por outro médico que não foi entrevistado, mas que participou da discussão para a aprovação do relatório da pesquisa. $\mathrm{O}$ roteiro de entrevistas utilizado contemplava quatro momentos: processo de trabalho; percepção da violência; vivência profissional perante situações de maus-tratos; e o atendimento "ideal" em situações de maus-tratos.

$\mathrm{Na}$ época em que se procedeu à investigação, o módulo de médico de família da Ilha da Conceição existia há três anos e meio, tendo sido instituído através da associação de moradores do bairro, para atender a população do morro. A população residente na área foi dividida em três setores de 150 a 250 famílias, com aproximadamente 800 a 900 pessoas por setor. Com o objetivo de informar a comunidade sobre o funcionamento do programa, foram realizadas reuniões por setor antes da inauguração do posto, explicando as diferen- ças em relação aos postos de saúde convencionais, com agenda ao invés de atendimento da demanda espontânea.

Cada dupla, médica mais auxiliar de enfermagem (equipe básica), é responsável por um setor. As auxiliares de enfermagem moram no bairro mas não no morro, e são conhecidas por toda a comunidade. Uma médica e duas auxiliares atuam no módulo desde sua inauguração, a terceira auxiliar está lá há três anos, e a segunda médica, há um ano e sete meses.

\section{Características da comunidade de moradores do Morro da Ilha da Conceição}

O morro situa-se num bairro antigo de Niterói, a Ilha da Conceição, e é habitado basicamente por famílias de pescadores, biscateiros e trabalhadores ou ex-funcionários de estaleiro. O número de desempregados e trabalhadores absorvidos pelo mercado informal cresce a cada ano. Este aumento foi constatado no recadastramento realizado anualmente pela equipe do programa. Muitos moradores pertencem a igrejas evangélicas localizadas na comunidade.

O morro é considerado tranqüilo em comparação a outras comunidades atendidas pelo Programa Médico de Família. Contudo o tráfico de drogas é um fato, e os conflitos envolvendo traficantes têm se tornado mais freqüentes: "O que está acontecendo, e não acontecia, é o tráfico, com a polícia subindo e trocando tiros" (auxiliar de enfermagem).

\section{O trabalho no módulo médico de família}

O trabalho desenvolve-se em duas etapas: um turno é utilizado para o atendimento individual no posto. São agendadas seis consultas de 1/2 hora cada uma. Os casos de urgência (sutura, crise de asma, criança com febre, etc.) são atendidos sem marcação prévia. O outro turno é reservado para o trabalho de campo. Nesse momento as duplas sobem o morro fazendo visitas domiciliares para a busca ativa de gestantes, crianças, hipertensos e diabéticos. As entrevistadas alertaram que, quando se sobe o morro, é preciso colocar limite na demanda por consultas domiciliares, pois todo mundo "adoece" quando a médica está lá. O horário do trabalho de campo também é uti- 
lizado para a realização de atividades de grupos de gestantes, adolescentes, etc.

A equipe de supervisão vai ao módulo uma vez por semana. É constituída por profissionais das áreas de epidemiologia, clínica médica, ginecologia e obstetrícia, cirurgia, assistência social e enfermagem. No período em que se efetuaram as entrevistas, pediatria e psiquiatria encontravam-se sem supervisão. As auxiliares de enfermagem agendam os pacientes, fazem a triagem, pré-consultas, curativos, administração de medicamentos e trabalho de campo, como, por exemplo, a visita diária que uma auxiliar fazia a uma doente deprimida. As auxiliares de enfermagem também executam as tarefas administrativas e as estatísticas, como solicitação de medicamentos, organização do arquivo, etc.

\section{Grau de satisfação, vantagens e dificuldades do trabalho no módulo}

Todos gostam de trabalhar no módulo do Programa Médico de Família. Os grupos foram apontados como atividades preferidas por uma médica e uma auxiliar. As auxiliares de enfermagem consideram gratificante trabalhar com a comunidade. Valorizam a possibilidade de conhecer melhor as pessoas, criar vínculos de amizade. Consideram também importante captar os casos antes da doença aparecer, principalmente através da busca ativa de crianças, e gostam dos grupos.

Uma médica com formação em pediatria, saúde pública e homeopatia, optou pela medicina de família em função da proposta, em que a grande vantagem é o profissional não ficar o tempo todo no consultório, dispondo de 50\% da carga horária para ir na casa dos pacientes, ver como as pessoas vivem, conhecer as famílias no lugar em que moram, entendendo melhor o contexto de suas vidas e suas doenças.

Se por um lado o trabalho facilita a aproximação dos pacientes, por outro implica muitas dificuldades, evidenciadas na relação com a comunidade. A proximidade com a família tem um lado que é estressante, cobra-se tudo do médico, todo o tempo tem que se falar dos limites, até onde vai a responsabilidade do profissional. Realizar um trabalho que extrapola o consultório leva o médico a constatar a falta de informação da população e a perceber a ineficácia de simplesmente tentar transmitir os conhecimentos da forma como o médico os apreende. A vivência no módulo mostra que é necessário ouvir mais do que falar, e a partir do que o paciente fala, tentar intervir. Os profissionais consideram a orientação um trabalho a longo prazo, cuja repercussão só é sentida algum tempo depois. Segundo eles, a presença diária na comunidade possibilita o reconhecimento da distância entre o modo como os pacientes vêem o mundo e suas próprias concepções. As diferenças aparecem nas dificuldades de comunicação, na linguagem. $\mathrm{O}$ fato de o médico não possuir uma formação voltada para a educação e a saúde, aprendendo a se expressar tecnicamente sem se preocupar com a capacidade de compreensão por parte dos pacientes, foi citado como um dos fatores que contribuem para criar obstáculos à comunicação entre médicos e pacientes.

A demanda por supervisão em saúde mental é uma solicitação de toda a equipe, submetida a uma enorme carga psicológica por parte da comunidade, as pessoas contam várias coisas, problemas com os quais os profissionais não estão preparados para lidar, queixas orgânicas e psíquicas. A falta de treinamento e as falhas na supervisão são consideradas prejudiciais ao desenvolvimento do trabalho.

Entre as dificuldades, referiram-se à pressão de quem tenta ser consultado sem agendamento prévio. Para uma médica, algumas pessoas não entendem o que é prevenção, têm o interesse dirigido unicamente para a assistência curativa, emergencial e imediatista. Querem chegar no posto a qualquer momento e ser sempre atendidas ("emergência para a população pode ser qualquer coisa”), ao mesmo tempo querem que o médico lhes dê atenção, respeitando o tempo da consulta (meia hora). Segundo uma auxiliar de enfermagem, "a comunidade não reconhece o valor da faceta não biológica do programa médico de família”.

\section{Percepção da violência e da violência doméstica}

$\mathrm{Na}$ visão de uma médica, violência é tudo o que agride física ou mentalmente, causando sofrimento à pessoa. As auxiliares de enfermagem também consideram que a violência vai além da agressão física, mas colocam os danos físicos na frente: "primeiro é a parte física, depois a moral". Como exemplo de violência, além das manifestações mais óbvias como estupro, "porrada", pessoa drogada que mata ou- 
tras, e tiroteio, a história de uma paciente usuária de drogas que se descobriu portadora do vírus HIV, no quarto mês de gestação, foi relatada como o caso de violência que mais chocou uma auxiliar de enfermagem.

A violência doméstica foi definida como aquela praticada na família (ex.: marido que espanca mulher, pais que maltratam os filhos deixando marcas ao bater, filha grávida que é expulsa de casa, estupro, pai que engravida filha). Enfatizou-se bastante a dificuldade de estabelecer limites, para a equipe o limite entre o exercício da autoridade e a violência tem que ser debatido, estabelecendo o que é inaceitável ou não para cada caso (uma palavra vale mais que um tapa). Uma médica considera a questão da violência muito profunda, abrangendo a violência contra o profissional e a violência contra a comunidade. Segundo a entrevistada, o médico está sozinho para decidir o que fazer, e muitas vezes age a partir de uma avaliação subjetiva do limite entre o aceitável e o intolerável em cada caso. Uma auxiliar referiu que algumas famílias têm uma visão bastante rígida a respeito desses limites, influenciadas pela religião, dizem que está na Bíblia, que têm que bater mesmo.

\section{Casos de maus-tratos domésticos relatados pela equipe}

Alguns casos foram contados e analisados a partir da ótica dos profissionais, que também fizeram propostas de intervenção:

\section{1o relato: abuso físico}

Ocorreu numa família em que o pai tem sífilis mas recusa se submeter ao tratamento (nunca foi ao módulo), tem o hábito de beber e bate muito na mulher e nas filhas (uma entre oito e nove anos e outra entre cinco e seis). A mãe levou a filha mais velha ao posto para fazer curativo numa suposta mordida de rato, o ferimento foi aberto pelo supervisor de cirurgia sendo extraído do braço da menina um espeto de churrasco, com a ponta queimada, medindo aproximadamente 10 centímetros de cumprimento. Apesar dos esforços da equipe e da assistente social supervisora, não se conseguiu que a menina ou a mãe contassem o que aconteceu. Para a equipe, o pai é o maior suspeito. A mãe e a filha foram encaminhadas para atendimento psicoterápico no posto de referência, mas não foram à consulta agendada nem ao módulo, evitando também encontrar com qualquer um da equipe, especialmente a médica e auxiliar responsáveis. $\mathrm{Na}$ ocasião das entrevistas este foi o caso que mais mobilizou a equipe, sendo que alguns se manifestaram no sentido de que até então nada havia sido feito concretamente, e responsabilizando os supervisores e coordenadores.

\section{2o relato: negligência e abuso físico}

Numa família com três filhos, o mais velho tem aproximadamente 11 anos de idade e é asmático. Quando a família veio morar na Ilha da Conceição, era um "menino bom, sem problemas, quase não saía de casa”. A mãe trabalha fora o dia inteiro (...), e deixava o filho mais velho cuidando dos irmãos, depois a avó passou a cuidar dos dois menores.

O menino apresentava crises freqüentes de asma, buscando atendimento no módulo, sempre sozinho. Nunca foi ao posto levado por um adulto. Nessas ocasiões, a médica não entregava a medicação nas mãos do garoto. Ela tratava o quadro agudo e mandava recado para que a mãe viesse ao posto conversar, e pegar a medicação do filho. Como a mãe não aparecia, a médica e a auxiliar de enfermagem iam até a casa da família. Conversavam tentando mostrar à mãe que o menino precisava de cuidados. A mãe culpava o filho por adoecer, exigia dele um comportamento não condizente com sua idade. Observando a falta de carinho da mãe e da avó, a médica tentou mostrar que o menino ainda era uma criança, que a atitude dele era conseqüência da falta de atenção com que era tratado, uma forma de solicitar afeto, mas as respostas sempre foram que o garoto não tinha jeito, que não adiantava falar com ele, que ele não obedecia e fazia tudo errado. A médica não observava melhora no quadro clínico do paciente, mas quando perguntava se ele estava tomando os remédios corretamente, a mãe dizia que sim (o menino certa vez desmentiu a mãe dizendo na sua frente que não tinha tomado nenhum remédio). Uma tarde ele chegou no módulo com uma crise de asma tão intensa que a médica chamou a avó e pediu que levasse o neto para a emergência do Hospital Getúlio Vargas Filho.

Ao longo do tempo em que veio acompanhando o caso, a médica observou a piora gradual, tanto do quadro clínico quanto do com- 
portamento do menino, que inicialmente ia à escola, conversava com o pessoal do posto, e depois acabou abandonando os estudos para ficar na rua, tornou-se cada vez mais arredio e deixou de procurar a equipe do módulo. Passou a ficar na rua e faltar a escola, sem que a mãe ou a avó tomassem alguma atitude para impedi-lo. As auxiliares de enfermagem vendo-o sem camisa, até tarde na rua, mandavamno para casa, tomar banho, jantar e dormir, para ir a aula na manhã seguinte. Para a auxiliar de enfermagem e a médica que acompanharam o caso, existe negligência da mãe e da avó, que não vêem o menino como uma criança. Elas o tratam como alguém mais velho do que ele é, como se tivesse condição de cuidar de si mesmo. Mudaram-se recentemente para Venda da Cruz, ocasionalmente o menino comparece ao posto, quando está em crise asmática, para ser atendido.

\section{3o relato: abuso psicológico}

A mãe, abandonada pelo marido, freqüenta a igreja evangélica da comunidade, apresenta traços de fanatismo religioso, e tem um companheiro da mesma igreja. Educa os filhos (um casal de adolescentes) com extrema rigidez, dentro das normas da igreja evangélica, cheia de proibições e regras, considerando pecado comportamentos como namorar, ir ao cinema, usar roupas curtas e decotadas, ler revistas dirigidas à juventude, enfim quer impedir na filha atitudes aceitáveis e esperadas dos adolescentes. O irmão se defendeu saindo de casa, atualmente não mora mais com a mãe. A filha, desde que a médica foi trabalhar no módulo, veio apresentando crises de depressão periódicas, durante as quais conversava com a médica, que tentava estimular a menina a reagir. Paralelamente, a médica constatava a intransigência da mãe, que também é sua paciente. A menina começou a namorar e se mostrava bem mais animada apesar das reclamações maternas, que só deixava os dois namorarem dentro de casa, sob sua vigilância. $\mathrm{O}$ casal ficou noivo, mas o noivado foi rompido depois que a mãe exigiu que os dois ficassem morando com ela após o casamento. Em conseqüência, a menina caiu em depressão profunda, que deflagrou um surto psicótico (gritava palavrões e xingava a mãe). No momento da entrevista encontrava-se internada no Hospital Psiquiátrico de Jurujuba. A mãe leva os fiéis da Igreja para rezar e cantar pela filha no hospital, dizendo que o demônio tomou conta do corpo da filha.

A médica acompanhou este caso durante dois anos, ao longo dos quais a paciente passou por mais de uma crise depressiva, identificou a situação de violência familiar, e a médica sentiu-se extremamente impotente por perceber que suas tentativas de intervenção, através de conversas com a menina, se mostraram ineficazes para possibilitar outros rumos à história.

\section{Outros casos citados}

Abuso sexual: um caso de incesto em que o pai engravidou a filha, a mãe saiu de casa com os filhos menores, e atualmente o pai mora com a filha e a criança nascida.

Negligência: casos de desnutrição, como numa família de quatro crianças, todas com baixo peso, e que só são levadas ao posto pela mãe quando estão doentes.

Violência conjugal: ao longo dos encontros aludiu-se ainda a situações freqüentes de violência física contra mulheres, praticada pelos companheiros. Com os médicos as pacientes costumam se abrir mais e falar a respeito das agressões; já para as auxiliares de enfermagem, geralmente dizem ter levado um tombo, ou algo parecido (às vezes as pacientes evitam ir ao módulo enquanto as marcas da agressão são muito evidentes).

\section{Propostas da equipe para uma atuação efetiva contra a violência doméstica}

- Deve-se ter consciência de que os resultados só serão percebidos a longo prazo e desde que a família aceite e queira a assistência. Quando a família não dá abertura, "não sei o que fazer" (auxiliar de enfermagem).

- A intervenção ao alcance do médico é conversar com a família, uma coisa difícil pois a criança é sempre culpabilizada, tida como peste, merecedora do tratamento que recebe. Seria importante ter uma pessoa que ficasse responsável por esses casos no módulo, que tivesse experiência a respeito. $\mathrm{O}$ "ideal” seria ter uma equipe multidisciplinar (um psicólogo, um psiquiatra e uma assistente social trabalhando juntos).

- É preciso primeiramente orientar, explicar para a paciente que ela está sendo violentada e pode buscar ajuda em instituições específicas 
como a Delegacia da Mulher. É fundamental incentivar a auto-estima dos pacientes que sofrem violência na comunidade. Com este fim, as médicas estão procurando discutir textos sobre a questão da cidadania, "as pessoas acham que o Estado tem que fazer tudo por elas, acho que elas não se olham, não olham pra dentro". - Em casos extremos, com risco de vida deve-se dividir a responsabilidade com a coordenação, discutindo possibilidades, tais como Conselho Tutelar, ou outras. Estes casos devem ter uma repercussão maior, é necessário acionar algum órgão. Nessas situações, o médico não pode caminhar sozinho.

A notificação obrigatória ao Conselho Tutelar foi questionada:

"Ao acionar o C.T. não há como preservar o médico. Talvez fosse bom ter o C.T. como uma consultoria discutindo o caso, mas sem necessariamente notificar."

A não-notificação ao C.T. também não resolve, por deixar o médico sozinho:

"Fica tudo muito solto (...) quando existe 'risco de vida'? Essa determinação também é relativa, varia de acordo com a pessoa que avalia o caso. A criança que teve um espeto de churrasco enfiado no braço não está sob risco?” (médica). - Quando o C.T. foi acionado, "não resolveu nada, ficou na mão do juiz" (auxiliar de enfermagem).

- Deveria ter um órgão de referência para encaminhar os casos de violência contra crianças que não fosse o Conselho Tutelar (escuta denúncias sobre o Conselho, que tirava a criança da família, que responsabilizava o médico, por conta disso nunca recorreu ao Conselho). Esse órgão deveria funcionar com pessoas em regime de plantão para passar o caso, deveriam ter disponibilidade para estar no módulo, trabalhando com a equipe, acompanhando o caso. Um órgão com profissionais de diferentes áreas.

- Ideal seria que o C.T. também tivesse esse profissional para dar orientação, acompanhar. - Uma das auxiliares propôs a implantação de um BIN (boletim individual de notificação) para registro dos maus-tratos.

\section{Considerações finais}

Este texto tentou mostrar que as propostas assistenciais com base na saúde das famílias podem contribuir para ampliar as perspectivas de prevenção da violência.
Tuesta (1997) chegou a conclusões semelhantes observando a atuação de profissionais de saúde na assistência à vítimas de violência conjugal. Foram entrevistados 15 profissionais de Centros Municipais de Saúde do Rio de Janeiro e 15 de Módulos do Programa Médico de Família de Niterói. Entre as conclusões, apresenta-se a seguinte constatação:

"No que diz respeito à atuação dos profissionais, nos casos em que identificaram mulheres em situação de violência, como já foi apontado, a abordagem foi diferenciada em ambos os modelos de atenção. Os profissionais do RJ, à exceção das duas psicólogas e de uma das assistentes sociais, optaram por tratar os problemas de saúde física e mental relacionados com a violência sem discutir nem aprofundar a questão propriamente da violência doméstica. No entanto, os profissionais do PMF consideraram não apenas o tratamento das conseqüências da violência, como também orientaram e aconselharam sobre esse problema, a fim de mostrar às mulheres as possibilidades para enfrentar a violência" (Tuesta, 1997: 152-153).

A abordagem da família, e o fortalecimento dos laços entre os profissionais de saúde e a população atendida, constituem importantes estratégias que podem contribuir para a prevenção, a identificação e a intervenção em situações de violência familiar. No Programa Médico de Família as equipes se encontram em posição estrategicamente favorável para intervir nas relações interpessoais familiares. Se por um lado os profissionais se vêem imersos nos mesmos problemas das comunidades em que trabalham, sendo afetados por estes problemas e necessitando estabelecer um limite entre o exercício das atividades técnicas, o compromisso profissional em situações nas quais podem interferir positivamente, e as questões mais difíceis e complexas, quando se deparam com a impotência para sozinhos mudar uma realidade que só será transformada pela ação e investimento coletivo, da sociedade como um todo, e também individual, dos sujeitos diretamente submetidos a tal realidade. Por outro lado a proximidade e os vínculos constituídos, permitem aprofundar as relações, viabilizando a orientação dos conflitos para formas de enfrentamento menos destrutivas, mais saudáveis. Nesta perspectiva, os profissionais de saúde da família se tornam atores da maior significância para o desenvolvimento das ações de prevenção da violência. 
Entretanto, cabe também lembrar que, cada vez mais, em qualquer esforço de combate à violência torna-se imprescindível contar com uma ampla rede de apoio social, composta por instituições de diversos setores como educação, saúde, justiça, segurança, cultura e trabalho, governamentais e não-governamentais. A interlocução e a integração de diferentes ato-

\section{Agradecimentos}

Cláudia Regina de Andrade Pereira, Geandro Ferreira Pinheiro e Valdir Sergio Ermida, alunos da 1a turma (1995) do Curso de Especialização em Saúde Coletiva na Modalidade de Residência do NESC/UFRJ, constituíram, juntamente comigo, a equipe de pesquisadores que realizou este trabalho.

Gostaria de agradecer às médicas Cláudia e Ana Lúcia, e às auxiliares de enfermagem Geni, Ana Lúcia e Neise, que tornaram possível, e tão agradável, a realização deste trabalho, e gostaria de agradecer, também, à Coordenação do Programa Médico de Família de Niterói por autorizar e apoiar sua realização. res e instituições em rede propiciam a sustentação necessária para a eficácia e continuidade das ações empreendidas a partir da compreensão da violência no contexto da complexidade histórica, social, cultural e psicológica, e privilegiando a extensão dos direitos de cidadania, inclusive na vigência das relações interpessoais e familiares.

\section{Referências}

COOBS/FMS 1998. Relatório de Atividades realizadas em 1997. Coordenadoria do Observatório de Saúde. Fundação Municipal de Saúde de Niterói.

SUAPS/FMS 1997. Relatório de Atividades realizadas em 1996. Superintendência de Análise e Programação em Saúde. Fundação Municipal de Saúde de Niterói.

Tuesta AJA 1997. Gênero e Violência no Âmbito Doméstico: A Perspectiva dos Profissionais de Saúde. Dissertação de Mestrado. Escola Nacional de Saúde Pública, Fundação Oswaldo Cruz, Rio de Janeiro, 162p. 